\title{
Expression and Clinical Significance of Concomitant FAK/SRC and p-Paxillin in Mobile Tongue Squamous Cell Carcinoma
}

\author{
STAMATIOS THEOCHARIS ${ }^{1,2^{*}}$, IOLY KOTTA-LOIZOU ${ }^{2,3^{*}}$, CONSTANTINOS GIAGINIS $^{2,4}$, \\ PARASKEVI ALEXANDROU ${ }^{2}$, EUGENE DANAS $^{2}$, GERASIMOS TSOUROUFLIS $^{2}$, \\ NIKOLAOS TSOUKALAS ${ }^{2}$, ROBERT H.A. COUTTS ${ }^{5}$, JASON TASOULAS ${ }^{2}$ and JERZY KLIJANIENKO ${ }^{1}$ \\ ${ }^{1}$ Department of Pathology, Curie Institute, Paris, France; \\ ${ }^{2}$ First Department of Pathology, Medical School, University of Athens, Athens, Greece; \\ ${ }^{3}$ Department of Life Sciences, Imperial College London, London, U.K.; \\ ${ }^{4}$ Department of Food Science and Nutrition, University of the Aegean, Lemnos, Greece; \\ ${ }^{5}$ Department of Biological and Environmental Sciences, University of Hertfordshire, Hatfield, U.K.
}

\begin{abstract}
Background/Aim: The focal adhesion kinase (FAK)/SRC phosphorylation cascade and its downstream target paxillin have been implicated in malignant transformation, tumor growth and progression, together with metastasis. The present study aimed to evaluate the clinical significance of concomitant FAK/SRC and p-paxillin expression in mobile tongue squamous cell carcinoma (SCC). Materials and Methods: FAK, SRC and phosphopaxillin expression in 48 mobile tongue SCC tissue samples was assessed immunohistochemically and analyzed with respect to clinicopathological characteristics and patient survival. Results: Concomitant high FAK/SRC expression was significantly associated with high grade of tumor differentiation $(p=0.048)$ and longer disease-free patient survival (log-rank test, $p=0.019)$. High p-paxillin expression was significantly associated with greater depth of invasion $(p=0.002)$, lymph node metastasis $(p=0.048)$ and poorer disease-free patient survival (log-rank test, $p=0.021$; Coxregression analysis, $p=0.031)$. Conclusion: The present study provides evidence that FAK/SRC and paxillin play a role in the pathophysiological aspects of mobile tongue SCC and could constitute therapeutic targets.
\end{abstract}

*These Authors contributed equally to this study.

Correspondence to: Ioly Kotta-Loizou, M.Sc., Ph.D. Department of Life Sciences, Imperial College London, Imperial College Road, SW7 2AZ, London, U.K. E-mail: i.kotta-loizou13@imperial.ac.uk

Key Words: Mobile tongue squamous cell carcinoma, FAK, SRC, paxillin, clinicopathological parameters, prognosis, immunohistochemistry.
Focal adhesion kinase (FAK) and proto-oncogene tyrosine protein kinase SRC are ubiquitously expressed non-receptor tyrosine kinases $(1,2)$. They are reciprocally activated by phosphorylation $(3,4)$ and the FAK/SRC dual kinase complex initiates multiple phosphorylation cascades, regulating several cellular functions, including integrinmediated cell adhesion and migration, angiogenesis, cell cycle, cell proliferation and apoptosis (5). A prominent phosphorylation substrate of the FAK/SRC kinase complex is paxillin $(6,7)$, which interacts with several proteins coordinating changes in the actin cytoskeleton associated with cell motility and cell adhesion.

The involvement of FAK/SRC in cellular pathways that regulate cell survival, growth, invasion and motility $(8,9)$ suggests that they contribute to the development of cancer and are putative drug targets for treatment (10-13). Similarly, paxillin has been implicated in tumor progression, angiogenesis and metastasis, either as a downstream target of FAK/SRC or in its own right (14-17). Clinical studies have revealed that FAK, SRC and paxillin expression are significantly correlated with clinicopathological parameters and patient survival in many cancer types (18-24).

Mobile tongue squamous cell carcinoma (SCC) is the most common malignancy diagnosed within the oral cavity (25). Despite advanced therapeutic strategies, the 5-year survival rate has not been considerably improved, mainly due to lymph node metastasis at diagnosis $(26,27)$. Therefore there is an urgent need to establish reliable prognostic markers in mobile tongue SCC. In light of the above considerations, the present study aimed to assess concomitant FAK/SRC and phospho (p)-paxillin expression levels immunohistochemically in 48 mobile tongue SCC samples, in association with clinicopathological parameters and patient survival. 


\section{Materials and Methods}

The medical records and archival histopathological material of the 48 patients with mobile tongue SCC included in this study were described in detail previously (28). Clinical and histopathological parameters were assessed according to standard criteria as described elsewhere (28). Immunostaining for FAK, SRC and p-paxillin was performed as described elsewhere (28-30), using primary antibodies detecting FAK, c-SRC and p-paxillin (Tyr118), respectively (all from Santa Cruz Biotechnology, Santa Cruz, CA, USA). Appropriate negative controls were performed by omitting the primary antibody or substituting it with an irrelevant anti-serum. As positive controls, pancreatic, thyroid and endometrial cancer tissue sections with known increased FAK and SRC immunoreactivity (29-31) and colon cancer tissue sections with known increased p-paxillin immunoreactivity (unpublished data) were used. The immunoreactivity was scored according to the percentage of FAK-, SRC- and p-paxillin-positive tumor cells as 0 : negative staining, $0-4 \%$ of cells positive; $1: 5-24 \%$ of cells positive; 2 : $25-49 \%$ of cells positive; $3: 50-100 \%$ of cells positive; and its intensity as 0 : negative staining; 1 : mild staining; 2 : intermediate staining; 3: intense staining. Expression was classified as low when the total score was $0-2$, and high, if the total score was $\geq 3(28,32,33)$. Concomitant high FAK/SRC expression was defined as cases presenting simultaneously high FAK and SRC expression, whereas concomitant low FAK/SRC expression was defined as cases presenting low expression in either FAK or SRC or both proteins. Statistical analysis was performed as described previously (28): chisquare test was used to assess the associations of concomitant FAK/SRC and p-paxillin expression with clinicopathological variables, Kaplan-Meier survival curves were compared by the logrank test and a Cox proportional-hazards regression model was developed to evaluate the association between potential prognostic markers and overall and disease-free survival. A $p$-value less than 0.05 was considered the limit of statistical significance.

\section{Results}

All 48 samples of mobile tongue SCC were found to stain positively for FAK, SRC and p-paxillin and representative immunostaining results are shown in Figure 1. Concomitant high FAK/SRC expression was positively associated with histological grade of tumor differentiation (Table I, $p=0.048$ ), whereas no associations with patient age and gender or any other clinicopathological parameters examined were recorded. High p-paxillin expression was significantly associated with greater depth of invasion and lymph node metastasis (Table I, $p=0.002$ and $p=0.048$, respectively).

Kaplan-Meier survival curves indicated that patients with mobile tongue SCC with concomitant high FAK/SRC expression presented non-significantly longer (Figure 2A, log-rank test, $p=0.057$ ) and those with high $\mathrm{p}$-paxillin expression shorter (Figure 2B, log-rank test, $p=0.226$ ) overall survival times compared to those with low expression. Longer overall patient survival was also significantly correlated with female gender and lesser depth of invasion (Table II, $p=0.010$ and $p=0.047$, respectively), while a trend for correlation of better survival with dense
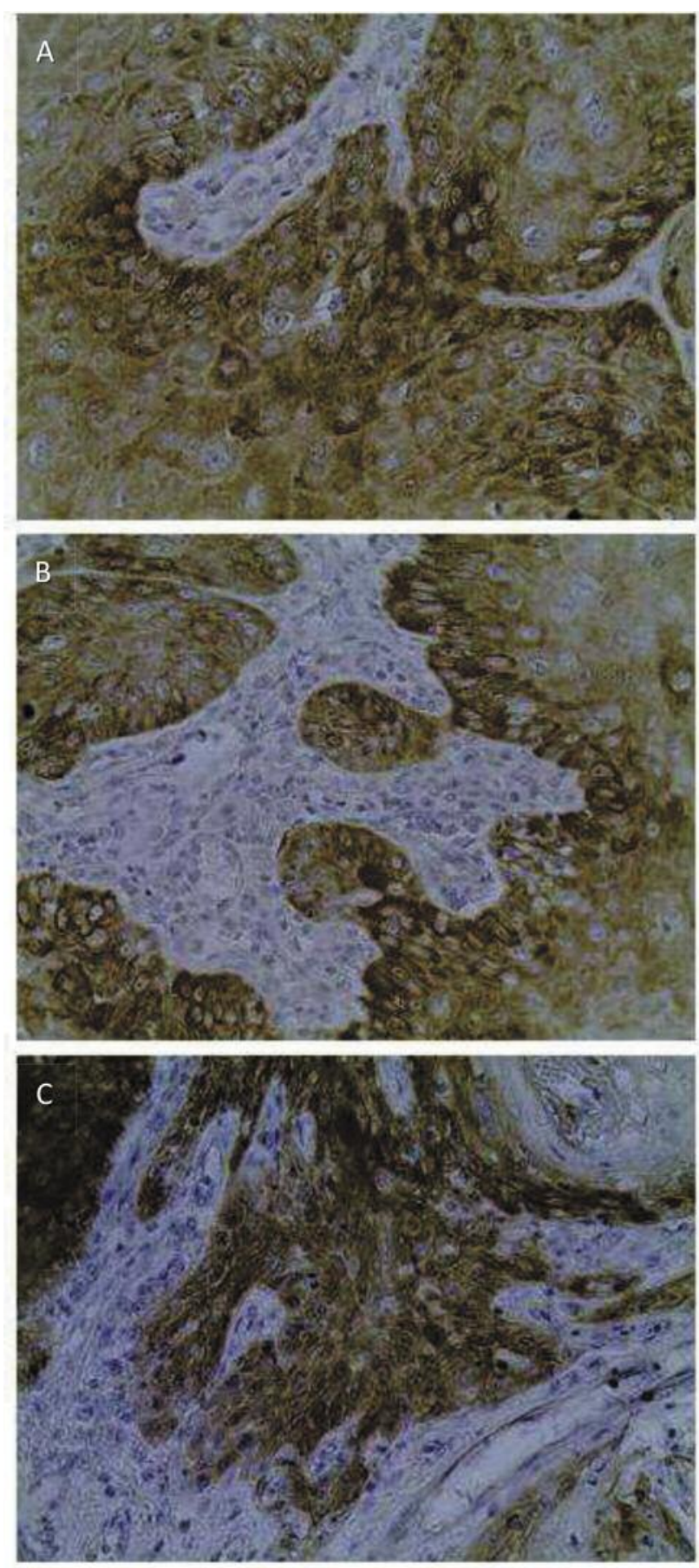

Figure 1. Representative immunostaining results for focal adhesion kinase (A), proto-oncogene tyrosine protein kinase SRC (B) and phospho-paxillin $(C)$ protein expression in tumor cells of mobile tongue squamous cell carcinoma. Streptavidin-biotin-peroxidase, 3,3diaminobenzidine $(D A B)$ chromogen, Harris hematoxylin counterstain (original magnification $\times 400)$.

stromal inflammatory reaction and well-defined tumor shape was noted ( $p=0.050$ and $p=0.069$, respectively). 
Table I. Associations of concomitant focal adhesion kinase (FAK)/proto-oncogene tyrosine protein kinase SRC and phospho-paxillin expression with clinicopathological parameters in 48 patients with mobile tongue squamous cell carcinoma.

\begin{tabular}{|c|c|c|c|c|c|c|}
\hline \multirow[t]{2}{*}{ Clinicopathological characteristic } & \multicolumn{3}{|c|}{ Concomitant FAK/SRC expression } & \multicolumn{3}{|c|}{ p-Paxillin expression } \\
\hline & Low, n (\%) & High, n (\%) & $p$-Value & Low, n (\%) & High, n (\%) & $p$-Value \\
\hline $\mathrm{N}=48$ & $33(68.8)$ & $15(31.2)$ & & $33(68.8)$ & $15(31.2)$ & \\
\hline Age mean \pm SD & & & 0.636 & & & 0.636 \\
\hline$\leq 62.2 \pm 14.6$ years & $20(41.7)$ & $8(16.7)$ & & $20(41.7)$ & $8(16.7)$ & \\
\hline$>62.2 \pm 14.6$ years & $13(27.1)$ & $7(14.6)$ & & $13(27.1)$ & $7(14.6)$ & \\
\hline Gender & & & 0.259 & & & 0.459 \\
\hline Male & $19(39.6)$ & $6(12.5)$ & & $16(33.3)$ & $9(18.8)$ & \\
\hline Female & $14(29.2)$ & $9(18.7)$ & & $17(35.4)$ & $6(12.5)$ & \\
\hline Histopathological grade & & & 0.048 & & & 0.369 \\
\hline I & $22(45.8)$ & $14(29.1)$ & & $26(54.2)$ & $10(20.8)$ & \\
\hline II & $11(22.9)$ & $1(2.1)$ & & $7(14.6)$ & $5(10.4)$ & \\
\hline Stromal inflammatory reaction & & & 0.457 & & & 0.175 \\
\hline Mild/moderate & $10(20.8)$ & $3(6.3)$ & & 7 (14.6) & $6(12.5)$ & \\
\hline Dense & $23(47.9)$ & $12(25.0)$ & & $26(54.2)$ & $9(18.8)$ & \\
\hline Muscular invasion & & & 0.869 & & & 0.473 \\
\hline Yes & $28(58.3)$ & $13(27.1)$ & & $29(60.4)$ & $12(25.0)$ & \\
\hline No & $5(10.4)$ & $2(4.1)$ & & $4(8.3)$ & $3(6.3)$ & \\
\hline Shape & & & 0.175 & & & 0.457 \\
\hline Diffuse & $26(54.3)$ & $9(18.7)$ & & 23 (47.9) & $12(25.0)$ & \\
\hline Well-defined & $7(14.6)$ & $6(12.5)$ & & $10(20.8)$ & $3(6.3)$ & \\
\hline Vascular invasion & & & 0.502 & & & 0.151 \\
\hline Yes & $6(12.5)$ & $4(8.3)$ & & $5(10.4)$ & $5(10.4)$ & \\
\hline No & $27(56.3)$ & $11(22.9)$ & & $28(58.3)$ & $10(20.8)$ & \\
\hline Perineural invasion & & & 0.269 & & & 0.636 \\
\hline Yes & $12(25.0)$ & $8(16.6)$ & & $13(27.1)$ & 7 (14.6) & \\
\hline No & $21(43.8)$ & $7(14.6)$ & & $20(41.7)$ & $8(16.7)$ & \\
\hline Depth of invasion & & & 0.839 & & & 0.002 \\
\hline $\mathrm{I}+\mathrm{II}$ & $21(43.8)$ & $10(20.8)$ & & $26(54.2)$ & $5(10.4)$ & \\
\hline III & $12(25.0)$ & $5(10.4)$ & & 7 (14.6) & $10(20.8)$ & \\
\hline Lymph node metastasis & & & 1.000 & & & 0.048 \\
\hline Yes & $11(22.9)$ & $5(10.4)$ & & $8(16.7)$ & $8(16.7)$ & \\
\hline No & $22(45.8)$ & $10(20.8)$ & & $25(52.1)$ & $7(14.6)$ & \\
\hline Mitotic index & & & 0.613 & & & 0.459 \\
\hline$\leq$ Median & $15(31.3)$ & $8(16.7)$ & & $17(35.4)$ & $6(12.5)$ & \\
\hline$>$ Median & $18(37.5)$ & 7 (14.6) & & $16(33.3)$ & $9(18.8)$ & \\
\hline
\end{tabular}

Univariate analysis also showed that patients with mobile tongue SCC with concomitant high FAK/SRC expression presented significantly longer disease-free survival times compared to those with low expression (Figure 2C, log-rank test, $p=0.019)$. Moreover, longer disease-free survival significantly correlated with female gender, well-defined tumor shape and high histological grade of tumor differentiation (Table II, $p=0.007, p=0.034$ and $p=0.040$, respectively), while a trend for correlation between diseasefree survival and dense stromal inflammatory reaction was also recorded $(p=0.054)$. However, concomitant FAK/SRC expression, as well as patient gender, and tumor grade and shape, did not remain significant in multivariate analysis concerning disease-free survival (Table III).
In contrast, Kaplan-Meier survival curves indicated that patients with mobile tongue SCC with high p-paxillin expression presented significantly shorter disease-free survival times compared to those with low expression (Figure 2D, log-rank test, $p=0.021$ ). In multivariate analysis, patient gender and p-paxillin expression were identified as independent factors associated with disease-free patient survival (Cox-regression analysis, $p=0.033$ and $p=0.031$, respectively).

\section{Discussion}

The role of the FAK/SRC/paxillin axis in human malignancy is well established (8-24) but its role in mobile tongue SCC is 

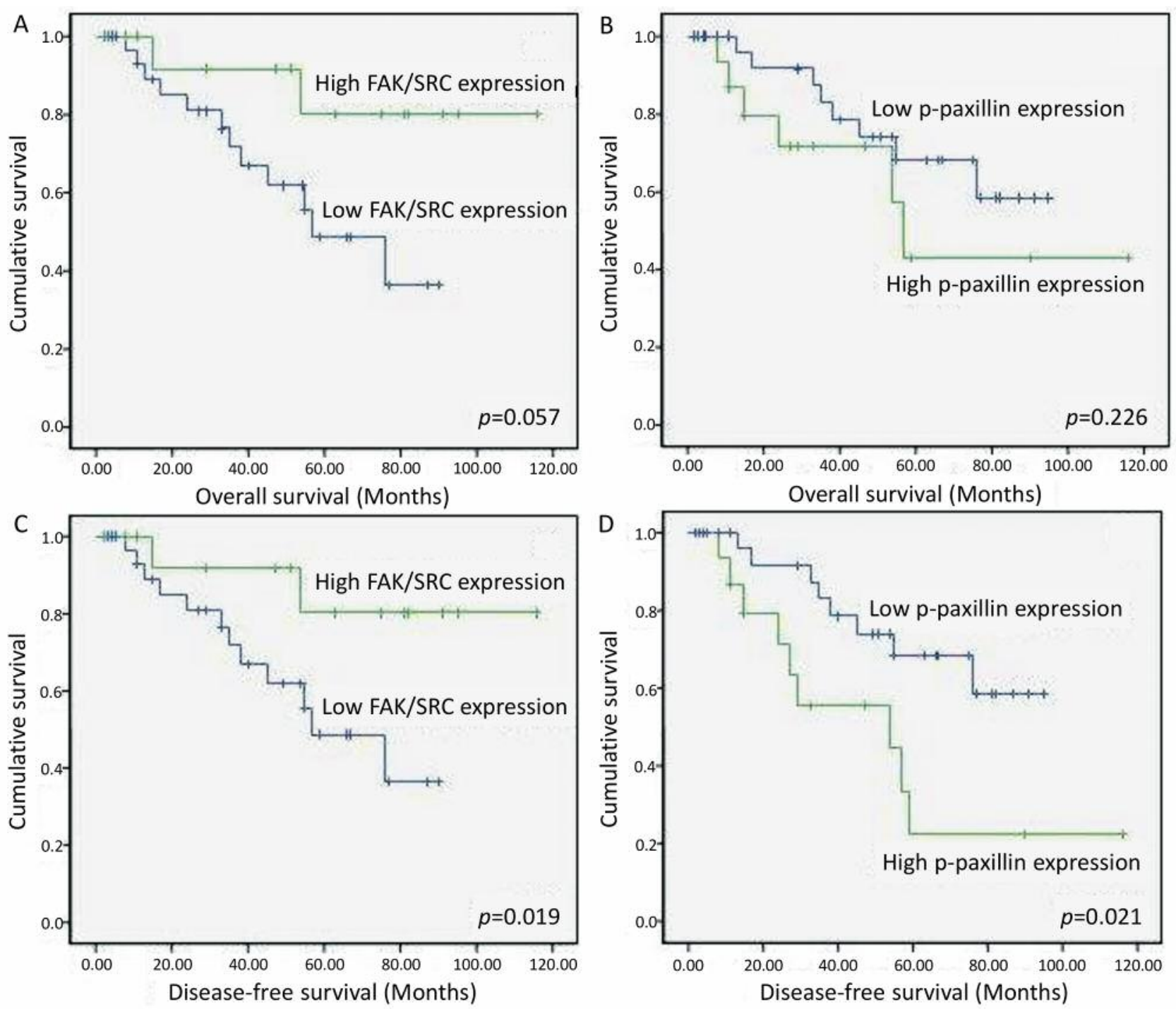

Figure 2. Kaplan-Meier survival analysis of overall $(A, B)$ and disease-free $(C, D)$ survival stratified according to concomitant focal adhesion kinase $(F A K) /$ proto-oncogene tyrosine protein kinase $S R C(A, C)$ and phospho-paxillin $(B, D)$ protein expression in patients with mobile tongue squamous cell carcinoma.

still being investigated. As an extension to our previous investigations (28), the present study evaluated the associations between concomitant FAK/SRC expression and clinicopathological parameters, together with overall and disease-free patient survival. We confirmed the correlation of concomitant FAK/SRC expression with high tumor differentiation grade, observed by Theocharis et al. for FAK and SRC separately, and illustrated the association of concomitant FAK/SRC expression with longer disease-free patient survival, noted previously for SRC only (28). Additionally, we investigated the possibility that p-paxillin, a downstream target of the FAK/SRC phosphorylation cascade, would show similar correlations. However we demonstrated the opposite effect suggesting that these proteins do not operate together in this context. More specifically, high p-paxillin expression was significantly associated with greater tumor depth of invasion and presence of lymph node metastasis, while patients with mobile tongue SCC with high p-paxillin expression presented significantly shorter disease-free survival times compared to those with low expression. Thus p-paxillin expression was identified as an independent factor in diseasefree patient survival. The present observations support the implication of FAK/SRC and p-paxillin signaling in disease progression and recurrence. However, the opposite associations noted between concomitant FAK/SRC, and p-paxillin expression with clinicopathological parameters and patient 
Table II. Association of clinicopathological parameters, concomitant focal adhesion kinase (FAK)/proto-oncogene tyrosine protein kinase SRC and phospho-paxillin expression with patient survival by univariate analysis.

\begin{tabular}{|c|c|c|c|c|}
\hline Clinicopathological parameters & Mean OS $(95 \%$ CI $)$, months & $p$-Value & Mean DFS $(95 \% \mathrm{CI})$, months & $p$-Value \\
\hline \multicolumn{5}{|l|}{ Age } \\
\hline$<62.2$ years & $65.2(50.9-79.5)$ & \multirow[t]{2}{*}{0.381} & $63.0(48.8-77.2)$ & \multirow[t]{2}{*}{0.607} \\
\hline$\geq 62.2$ years & $87.2(66.4-108.0)$ & & $78.3(57.3-99.3)$ & \\
\hline \multicolumn{5}{|l|}{ Gender } \\
\hline Male & $55.9(41.1-70.7)$ & \multirow[t]{2}{*}{0.010} & $51.7(37.6-65.9)$ & \multirow[t]{2}{*}{0.007} \\
\hline Female & $100.5(84.5-116.4)$ & & $95.4(78.0-112.8)$ & \\
\hline \multicolumn{5}{|l|}{ Histopathological grade } \\
\hline I & $85.5(69.4-101.7)$ & \multirow[t]{2}{*}{0.179} & $82.8(66.8-98.9)$ & \multirow[t]{2}{*}{0.040} \\
\hline II & $46.2(35.0-54.4)$ & & $41.7(31.1-52.4)$ & \\
\hline \multicolumn{5}{|l|}{ Stromal inflammatory reaction } \\
\hline Mild, moderate & $53.9(37.0-70.8)$ & \multirow[t]{2}{*}{0.050} & $50.4(33.9-66.9)$ & \multirow[t]{2}{*}{0.054} \\
\hline Dense & $90.3(74.2-106.4)$ & & $84.1(67.5-100.7)$ & \\
\hline \multicolumn{5}{|l|}{ Muscular invasion } \\
\hline Yes & $55.0(38.7-68.8)$ & \multirow[t]{2}{*}{0.554} & $49.4(35.5-63.3)$ & \multirow[t]{2}{*}{0.995} \\
\hline No & $78.9(63.4-94.3)$ & & $74.7(59.5-89.9)$ & \\
\hline \multicolumn{5}{|l|}{ Shape } \\
\hline Diffuse & $63.3(50.6-76.0)$ & \multirow[t]{2}{*}{0.069} & $58.3(46.1-70.5)$ & \multirow[t]{2}{*}{0.034} \\
\hline Well-defined & $105.8(87.6-124.0)$ & & $105.8(87.6-124.0)$ & \\
\hline \multicolumn{5}{|l|}{ Vascular invasion } \\
\hline Yes & $57.4(35.9-78.8)$ & \multirow[t]{2}{*}{0.418} & $57.4(35.9-78.8)$ & \multirow[t]{2}{*}{0.645} \\
\hline No & $83.7(67.7-99.7)$ & & $76.7(60.8-92.6)$ & \\
\hline \multicolumn{5}{|l|}{ Perineural invasion } \\
\hline Yes & $72.3(52.2-87.4)$ & \multirow[t]{2}{*}{0.533} & $72.3(57.2-87.4)$ & \multirow[t]{2}{*}{0.185} \\
\hline No & $74.8(54.2-95.4)$ & & $64.8(45.8-83.7)$ & \\
\hline \multicolumn{5}{|l|}{ Depth of invasion } \\
\hline $\mathrm{I}+\mathrm{II}$ & $77.8(66.3-89.3)$ & \multirow[t]{2}{*}{0.047} & $71.1(59.0-83.1)$ & \multirow[t]{2}{*}{0.177} \\
\hline III & $63.5(39.2-87.7)$ & & $63.5(39.2-87.7)$ & \\
\hline Lymph node metastasis & & & & \\
\hline Yes & $63.2(45.9-80.5)$ & 0.595 & $59.8(42.5-77.0)$ & 0.631 \\
\hline No & $82.7(64.7-100.6)$ & & $76.8(59.3-94.4)$ & \\
\hline Mitotic index & & & & \\
\hline$\leq$ Median & $82.2(62.7-101.6)$ & 0.977 & $73.8(54.3-93.2)$ & 0.831 \\
\hline$>$ Median & $67.7(53.4-81.9)$ & & $64.7(50.1-79.3)$ & \\
\hline Concomitant FAK/SRC expressi & & & & \\
\hline Low & $59.5(47.2-71.8)$ & 0.057 & $54.4(42.7-66.1)$ & 0.019 \\
\hline High & $100.5(80.9-120.0)$ & & $100.5(80.9-120.0)$ & \\
\hline p-Paxillin expression & & & & \\
\hline Low & $74.1(62.1-86.1)$ & 0.226 & $74.1(62.1-86.1)$ & 0.021 \\
\hline High & $69.9(43.8-96.0)$ & & $53.4(31.8-75.1)$ & \\
\hline
\end{tabular}

OS: Overall survival; DFS: disease-free survival; CI: confidence interval.

survival suggest that FAK/SRC and paxillin mediate their effects independently. High p-paxillin expression in mobile tongue SSC is probably controlled by other signaling pathways and leads to poor prognosis in contrast to the positive prognosis associated with high FAK/SRC expression, attesting to the complexity of molecular interactions in clinical samples. It should be noted that paxillin also has an upstream regulatory role on the FAK/SRC complex by mediating its localization at focal adhesions $(3,34,35)$. Interestingly, Conway et al. (36) reported that paxillin over-expression represses FAK phosphorylation in SCC25 tongue squamous cancer cells.
In support of the above findings, Jiang et al. documented a significant increase in FAK protein expression levels in welldifferentiated tongue tumors compared to poorly-differentiated types (37). Additionally, increased paxillin expression levels were associated with lymph node metastasis and shorter overall survival times in tongue SCC (38). Similar correlations between high paxillin expression and advanced clinicopathological parameters together with poor prognosis have been noted in salivary adenoid cystic carcinoma (39) and laryngeal SCC (40). In general, FAK and SRC constitute promising targets for anticancer therapy $(11,13)$. Taking into 
Table III. Association of clinicopathological parameters and concomitant focal adhesion kinase (FAK)/proto-oncogene tyrosine protein kinase SRC and phospho-paxillin expression with disease-free patient survival by multivariate analysis.

\begin{tabular}{|c|c|c|c|c|}
\hline \multirow[t]{3}{*}{ Variable } & \multicolumn{4}{|c|}{ Disease-free-survival } \\
\hline & \multicolumn{2}{|c|}{ Concomitant FAK/SRC } & \multicolumn{2}{|c|}{ p-Paxillin } \\
\hline & HR $(95 \% \mathrm{CI})$ & $p$-Value & HR $(95 \% \mathrm{CI})$ & $p$-Value \\
\hline Gender: Female vs. male & $0.284(0.075-1.080)$ & 0.065 & $0.282(0.088-0.902)$ & 0.033 \\
\hline Tumor grade: II vs. I & $1.988(0.590-6.701)$ & 0.268 & $3.014(0.972-9.347)$ & 0.056 \\
\hline Tumor shape: Well-defined $v s$. diffuse & $0.203(0.026-1.600)$ & 0.130 & $0.148(0.019-1.178)$ & 0.071 \\
\hline Protein expression: High $v s$. low & $0.381(0.077-1.879)$ & 0.236 & $3.148(1.110-8.928)$ & 0.031 \\
\hline
\end{tabular}

HR: Hazard ratio; CI: confidence interval.

consideration the results of the present study, the FAK/SRC pathway could be targeted indirectly in order to increase and not inhibit signaling. Although no paxillin inhibitors are available to date (41), this molecule could also have potential therapeutic utility in mobile tongue SCC.

The present study provides evidence that the FAK/SRC/paxillin axis may play a role in the pathophysiological aspects of mobile tongue SCC, being associated with crucial clinicopathological parameters for patient management and prognosis. However the current investigation only concerned a limited number of patients and relatively few clinical events, limiting our ability to draw more precise conclusions. Further investigations should utilize a larger patient cohort to assess FAK and SRC activity. Both would be monitored by quantifying their activated-phosphorylated forms together with investigations of other downstream targets, apart from paxillin, in order to establish their clinical significance and therapeutic potential in mobile tongue SCC. Additionally, future research effort should focus on the assessment of the exact role of paxillin in the pathophysiological aspects that affect disease progression and prognosis in mobile tongue SCC.

\section{References}

1 Guan JL and Shalloway D: Regulation of focal adhesionassociated protein tyrosine kinase by both cellular adhesion and oncogenic transformation. Nature 358: 690-692, 1992.

2 Anderson SK, Gibbs CP, Tanaka A, Kung HJ and Fujita DJ: Human cellular $S R C$ gene: nucleotide sequence and derived amino acid sequence of the region coding for the carboxy-terminal twothirds of pp60c-src. Mol Cell Biol 5: 1122-1129, 1985.

3 Schlaepfer DD, Hauck CR and Sieg DJ: Signalling through focal adhesion kinase. Prog Biophys Mol Biol 71: 435-478, 1999.

4 Cohen LA and Guan JL: Mechanisms of focal adhesion kinase regulation. Curr Cancer Drug Targets 5: 629-643, 2005.

5 Zhao X and Guan JL: Focal adhesion kinase and its signaling pathways in cell migration and angiogenesis. Adv Drug Deliv Rev 63: 610-615, 2011.
6 Bellis SL, Miller JT and Turner CE: Characterization of tyrosine phosphorylation of paxillin in vitro by focal adhesion kinase. $\mathrm{J}$ Biol Chem 270: 17437-17441, 1995.

7 Thomas JW, Cooley MA, Broome JM, Salgia R, Griffin JD, Lombardo CR and Schaller MD: The role of focal adhesion kinase binding in the regulation of tyrosine phosphorylation of paxillin. J Biol Chem 274: 36684-36692, 1999.

8 Siesser PM and Hanks SK: The signalling and biological implications of FAK overexpression in cancer. Clin Cancer Res 12: 3233-3237, 2006.

9 Provenzano PP and Keely PJ: The role of focal adhesion kinase in tumor initiation and progression. Cell Adh Migr 3: 347-350, 2009.

10 Laird AD and Cherrington JM: Small molecule tyrosine kinase inhibitors: clinical development of anticancer agents. Expert Opin Investig Drugs 12: 51-64, 2003.

11 Chatzizacharias NA, Kouraklis GP and Theocharis SE: Focal adhesion kinase: a promising target for anticancer therapy. Expert Opin Ther Targets 11: 1315-1328, 2007.

12 Golubovskaya VM: Focal adhesion kinase as a cancer therapy target. Anticancer Agents Med Chem 10: 735-741, 2010.

13 Aleshin A and Finn RS: SRC: a century of science brought to the clinic. Neoplasia 12: 599-607, 2010.

14 Chen JY, Tang YA, Huang SM, Juan HF, Wu LW, Sun YC, Wang SC, Wu KW, Balraj G, Chang TT, Li WS, Cheng HC and Wang YC: A novel sialyltransferase inhibitor suppresses FAK/paxillin signaling and cancer angiogenesis and metastasis pathways. Cancer Res 71: 473-483, 2011.

15 Sero JE, Thodeti CK, Mammoto A, Bakal C, Thomas S and Ingber DE: Paxillin mediates sensing of physical cues and regulates directional cell motility by controlling lamellipodia positioning. PLoS One 6: e28303, 2011.

16 Huang SM, Hsu PC, Chen MY, Li WS, More SV, Lu KT and Wang YC: The novel indole compound SK228 induces apoptosis and FAK/paxillin disruption in tumor cell lines and inhibits growth of tumor graft in the nude mouse. Int J Cancer 131: 722732, 2012.

17 German AE, Mammoto T, Jiang E, Ingber DE and Mammoto A: Paxillin controls endothelial cell migration and tumor angiogenesis by altering neuropilin 2 expression. J Cell Sci 127: 1672-1683, 2014.

18 Chatzizacharias NA, Kouraklis GP and Theocharis SE: Clinical significance of FAK expression in human neoplasia. Histol Histopathol 23: 629-650, 2008. 
19 Chatzizacharias NA, Kouraklis GP, Giaginis CT and Theocharis SE: Clinical significance of SRC expression and activity in human neoplasia. Histol Histopathol 27: 677-692, 2012.

20 Chen DL, Wang ZQ, Ren C, Zeng ZL, Wang DS, Luo HY, Wang F, Qiu MZ, Bai L, Zhang DS, Wang FH, Li YH and Xu RH: Abnormal expression of paxillin correlates with tumor progression and poor survival in patients with gastric cancer. $\mathrm{J}$ Transl Med 11: 277, 2013.

21 Panousis D, Xepapadakis G, Lagoudianakis E, Karavitis G, Salemis N, Koronakis N, Patsouris E, Koronarchis D, Grosomanidis D, Chryssikos G, Ntasiou P, Kyriakidou V, Athanassiadou AM and Athanassiadou P: Prognostic value of EZH2, paxillin expression and DNA ploidy of breast adenocarcinoma: correlation to pathologic predictors. J BUON 18: 879-885, 2013.

22 Liu Z, Yang Z, Jiang S, Zou Q, Yuan Y, Li J, Li D, Liang L, Chen $\mathrm{M}$ and Chen S: Paxillin and carbonic anhydrase IX are prognostic markers in gallbladder squamous cell/adenosquamous carcinomas and adenocarcinomas. Histopathology 64: 921-934, 2014.

23 Xiao LJ, Zhao EH, Zhao S, Zheng X, Zheng HC, Takano Y and Song HR: Paxillin expression is closely linked to the pathogenesis, progression and prognosis of gastric carcinomas. Oncol Lett 7: 189-194, 2014.

24 Yin H, Zhang Q, Wang X, Li T, Wan Y, Liu Y and Zhu J: Role of paxillin in colorectal carcinoma and its relationship to clinicopathological features. Chin Med J 127: 423-429, 2014.

25 Bello IO, Soini Y and Salo T: Prognostic evaluation of oral tongue cancer: means, markers and perspectives (I). Oral Oncol 46: 630-635, 2010.

26 Sano D and Myers JN: Metastasis of squamous cell carcinoma of the oral tongue. Cancer Metastasis Rev 26: 645-662, 2007.

27 Shiboski CH, Schmidt BL and Jordan RC: Tongue and tonsil carcinoma: increasing trends in the U.S. population ages 20-44 years. Cancer 103: 1843-1849, 2005.

28 Theocharis S, Klijanienko J, Giaginis C, Alexandrou P, Patsouris $\mathrm{E}$ and Sastre-Garau X: FAK and SRC expression in mobile tongue squamous cell carcinoma: associations with clinicopathological parameters and patients survival. J Cancer Res Clin Oncol 138: 1369-1377, 2012.

29 Michailidi C, Giaginis C, Stolakis V, Alexandrou P, Klijanienko J, Delladetsima I, Chatzizacharias N, Tsourouflis G and Theocharis S: Evaluation of FAK and SRC expression in human benign and malignant thyroid lesions. Pathol Oncol Res 16: 497-507, 2010.

30 Chatzizacharias NA, Giaginis C, Gatzidou E, Tsourouflis G, Sfiniadakis I, Alexandrou P and Theocharis SE: Expression and clinical significance of FAK and SRC proteins in human endometrial adenocarcinoma. Pathol Oncol Res 17: 277-285, 2011.

31 Chatzizacharias NA, Giaginis C, Zizi-Serbetzoglou D, Kouraklis GP, Karatzas G and Theocharis SE: Evaluation of the clinical significance of focal adhesion kinase and SRC expression in human pancreatic ductal adenocarcinoma. Pancreas 39: 930-936, 2010.

32 Theocharis S, Klijanienko J, Giaginis C, Rodriguez J, Jouffroy T, Girod A, Point D, Tsourouflis G and Sastre-Garau X: Metallothionein expression in mobile tongue squamous cell carcinoma: associations with clinicopathological parameters and patient survival. Histopathology 59: 514-525, 2011.

33 Theocharis S, Klijanienko J, Giaginis C, Alexandrou P, Patsouris E and Sastre-Garau X: Ephrin Receptor (Eph) -A1, -A2, -A4 and -A7 expression in mobile tongue squamous cell carcinoma: associations with clinicopathological parameters and patients survival. Pathol Oncol Res 20: 277-284, 2013.
34 Zachary I: Focal adhesion kinase. Int J Biochem Cell Biol 29: 929-934, 1997.

35 Cary LA and Guan JL: Focal adhesion kinase in integrinmediated signaling. Front Biosci 4: D102-113, 1999.

36 Conway WC, Van der Voort van Zyp J, Thamilselvan V, Walsh MF, Crowe DL and Basson MD: Paxillin modulates squamous cancer cell adhesion and is important in pressure-augmented adhesion. J Cell Biochem 98: 1507-1516, 2006.

37 Jiang H, Liu L, Ye J, Liu H, Xing S and Wu Y: Focal adhesion kinase serves as a marker of cervical lymph node metastasis and is a potential therapeutic target in tongue cancer. J Cancer Res Clin Oncol 136: 1295-1302, 2010.

38 Kurokawa A, Nagata M, Kitamura N, Noman AA, Ohnishi M, Ohyama T, Kobayashi T, Shingaki S and Takagi R: Diagnostic value of integrin alpha3, beta4, and beta5 gene expression levels for the clinical outcome of tongue squamous cell carcinoma. Cancer 112: 1272-1281, 2008.

39 Shi J, Wang S, Zhao E, Shi L, Xu X and Fang M: Paxillin expression levels are correlated with clinical stage and metastasis in salivary adenoid cystic carcinoma. J Oral Pathol Med 39: 548551,2010 .

40 Gao W, Zhang C, Feng Y, Chen G, Wen S, Huangfu H and Wang B: Fascin-1, ezrin and paxillin contribute to the malignant progression and are predictors of clinical prognosis in laryngeal squamous cell carcinoma. PLoS One 7: e50710, 2012.

41 Kratimenos P, Koutroulis I, Marconi D, Syriopoulou V, Delivoria-Papadopoulos M, Chrousos GP and Theocharis S: Multi-targeted molecular therapeutic approach in aggressive neuroblastoma: the effect of focal adhesion kinase-SRC-paxillin system. Expert Opin Ther Targets 18: 1395-1406, 2014.

42 Xia J, Lv N, Hong Y, Li C, Tao X, Chen X and Cheng B: Increased expression of focal adhesion kinase correlates with cellular proliferation and apoptosis during 4-nitroquinoline-1-oxide-induced rat tongue carcinogenesis. J Oral Pathol Med 38: 524-529, 2009.

43 Ben-Izhak O, Cohen-Kaplan V and Nagler RM: The prognostic role of phospho-SRC family kinase analysis in tongue cancer. $\mathrm{J}$ Cancer Res Clin Oncol 136: 27-34, 2010.

44 Kim SA, Kwon SM, Kim JA, Kang KW, Yoon JH and Ahn SG: 5'-Nitro-indirubinoxime, an indirubin derivative, suppresses metastatic ability of human head and neck cancer cells through the inhibition of Integrin beta1/FAK/AKT signaling. Cancer Lett 306: 197-204, 2011.

45 Ho YT, Yang JS, Li TC, Lin JJ, Lin JG, Lai KC, Ma CY, Wood WG and Chung JG: Berberine suppresses in vitro migration and invasion of human SCC-4 tongue squamous cancer cells through the inhibitions of FAK, IKK, NF-kappaB, u-PA and MMP-2 and -9. Cancer Lett 279: 155-162, 2009.

46 Cheng SJ, Kok SH, Lee JJ, Yen-Ping Kuo M, Cheng SL, Huang YL, Chen HM, Chang $\mathrm{HH}$ and Chiang CP: Significant association of SRC protein expression with the progression, recurrence, and prognosis of oral squamous cell carcinoma in Taiwan. Head Neck 34: 1340-1345, 2011. 